\title{
TESTING RATIONAL EXPECTATIONS HYPOTHESIS IN THE MANUFACTURING SECTOR IN MALAYSIA
}

\author{
Chin-Hong Puah ${ }^{1}$, Shirly Siew-Ling Wong ${ }^{2}$, Venus Khim-Sen Liew ${ }^{3}$ \\ Department of Economics, Faculty of Economics and Business, \\ University Malaysia Sarawak, 94300 Kota Samarahan, Sarawak, Malaysia \\ E-mails: ${ }^{1}$ chpuah@feb.unimas.my (corresponding author); \\ 2shirlywong87@hotmail.com; ${ }^{3}$ ksliew@feb.unimas.my
}

Received 24 June 2011; accepted 10 October 2011

\begin{abstract}
The application of rational expectations hypothesis (REH) in macroeconomic research has marked a revolution in economic thinking, and the magnitude of its impact on the world of economics is undeniably significant. However, the extent to which REH applies in real-world settings is ambiguous even though the concept of REH is well established in economics literature because empirical evidence from previous studies is clearly mixed. This study used survey data on gross revenue and capital expenditures to examine the validity of REH in Malaysian manufacturing business expectations. Empirical results indicated that the manufacturers' expectations are being irrationally constructed in terms of gross revenue predictions but comply with REH properties in Muth's sense in the case of capital expenditures forecasts. Therefore, manufacturing firms in Malaysia are encouraged to incorporate more relevant information into their gross revenue predictions to provide more accurate and realistic forecasting.
\end{abstract}

Keywords: rational expectations hypothesis, unbiasedness test, non-serial correlation test, weak-form efficiency test.

Reference to this paper should be made as follows: Puah, Ch.-H.; Wong, Sh. S.-L.; Liew, V. K.-S. 2013. Testing rational expectations hypothesis in the manufacturing sector in Malaysia, Journal of Business Economics and Management 14(2): 303-316.

JEL Classification: C12, C32, C51, D84.

\section{Introduction}

The rational expectations hypothesis (REH) is a theoretically attractive framework for assessing the mechanism with which economic agents process information when formulating judgments about the real world (Krause 2000). REH is largely applied to the study of price forecasts, exchange rates, or interest rate expectations; it also serves as a methodology for understanding the expectations formation mechanism in monetary policy designs. Although the theoretical soundness of REH has been firmly established, its empirical support is an ongoing question. First, there are no conclusive and convincing arguments on how the theory of rational expectations should be tested. In other words, economists are ambiguous about whether to use direct tests based on survey data 
(Aggarwal, Mohanty 2000) or indirect tests with constructed measures of expectations to test REH in empirical studies as both tests possess merits and shortcomings.

Testing the validity of REH by employing indirect tests based on constructed measures of expectations as proposed by Muth (1961) always involves testing the REH as well as the underlying model specification. Thus, a rejection of the joint hypothesis may be due to the rejection of REH or other hypothesis (Beach et al. 1995). Even so, indirect testing is widely applied by researchers in REH testing because Muth's indirect testing procedure incorporates actual market outcome. However, Keane and Runkle (1990), Beach et al. (1995), Osterberg (2000), Forsells and Kenny (2002), Mitchell and Pearce (2007), Gao et al. (2008), and many other proponents of survey-based expectations tend to use survey data as a proxy for market expectations to overcome the problems created by joint testing. This is because REH testing based on survey data collected from individual responses can provide empirical support directly, without the need to account for additional economic models. The suitability of survey data in REH testing was highlighted in Frankel and Foot (1987), Keane and Runkle (1990), Kim (1997), Nielsen (2003) as well as Dovern and Weisser (2008). Despite the diligent study of survey measures of expectations, the ability of survey materials to reflect the economic agent's true expectations is still unconvincing as empirical support provided by previous studies is decisively mixed.

Furthermore, it is worth noting that most literature on REH is concentrated on the developed countries, including the work of Madsen (1993) on Denmark, Finland, France, Germany, Japan, the Netherlands, Norway, Sweden, and the UK; Lovell (1986), and Baghestani and Kianian (1993) in turn tested the empirical relevance of REH in various economic sectors of the US economy; Kim (1997) studied Austria; Aggarwal and Mohanty (2000) studied Japan, whereas Nielsen (2003) and Dias et al. (2010) studied the European Union and European countries, respectively. Only a few studies have empirically examined REH in developing countries. For instance, via indirect measure of expectations, Ghaffar and Habibullah (1987), and Habibullah (1988) evidenced that rational forecasts hold true for price expectations within the frameworks of Malaysian money demand as well as loan decisions formed by agricultural producers in Malaysia. On the other hand, using direct test approach, Habibullah (1994, 1996, 2001), Puah et al. (2011) and Wong et al. (2011) studied REH in Malaysia's agricultural and business sectors through survey series of business expectations, while Marais, Smit and Conradie (1997) performed a micro-level test on REH in South Africa. Notwithstanding, additional study on this research topic to supplement past studies is indeed essential to provide better insight into the understanding of expectation formation mechanisms in developing countries.

Since the 1980s, many researchers have focused on rationality testing in the manufacturing sector, including De Leeuw and McKelvey (1981, 1984), Tompkinson and Common (1983), Kawasaki and Zimmermman (1986). De Leeuw and McKelvey (1981, 1984) reported that price expectations of US business firms were biased, implying that REH did not apply to US manufacturing firms. Tompkinson and Common (1983) examined the expectational rationality of business firms in British manufacturing sectors 
and found that decision makers in the British manufacturing sector in general did not act rationally in Muth's sense. Kawasaki and Zimmermman (1986) investigated the rationality of Germany's business firms in price expectations and their findings indicated that Germany's manufacturers did not act under the doctrine of REH when calculating price expectations.

On the other hand, Madsen (1993) studied production expectations in the manufacturing sector of nine industrial countries and reported that production expectations were not formed under the principle of REH. Another contributory empirical study was attributable to Marais, Smit and Conradie (1997), they discovered that entrepreneurs in South Africa did not form their future forecasts under the framework of REH. In the case of Malaysia, there is thus far no distinct empirical study investigating specifically the manufacturing sector other than Habibullah (1994), who examined the validity of REH in a Malaysian business context that also included the manufacturing sector. Hence, further empirical testing of the rationality of survey forecasts is undoubtedly welcomed as evaluation of forecast accuracy and REH validity from the Malaysian perspective is still an open issue.

We built the rationality testing on value-related business operational forecasts on manufacturing sector with the concern that the dynamic nature of the Malaysia's manufacturing sector manifested the need for a sound understanding on the current trend as well as future outlook of the sector within the economy. The survey of business forecasts, if and when uphold by the empirical foundation of REH, would serve as an efficacious input to a successful business planning, particularly on production and investment decisions. As claimed by Kozlinskis and Guseva (2006), the business surveys play an important role in short-term economic forecasting, surveillance and monitoring of economic development. Hence, the insight into the behavioral basis of the decision makers which ultimately shaped the expectations formation mechanism for the manufacturing sector will certainly furnish the policymakers with useful information for policy establishments on national realm, besides facilitating the industry-specified development planning.

Concisely, the main objective of this study was to evaluate empirically the rationality of manufacturing firms' expectations on their operational variables, including gross revenue and capital expenditures, using survey expectational data extracted from the Business Expectations Survey of Limited Companies (BESLC) compiled by the Department of Statistics Malaysia (DOSM). The rest of this paper is organized as follows: Section 2 explains the theoretical basis of REH and section 3 briefly discusses the data description and methodology involved in the study. The empirical results are presented in section 4 and section 5 concludes.

\section{Theoretical basics: properties of REH}

The basic concepts of rational expectations assume that expectations are formed based on the relevant economic structure given all useful information available when the forecasts are made. Muth defined the concept of rational expectations using the following Equation (1): 


$$
\Pi_{t}^{*}=E\left(\Pi_{t} \mid \mathrm{I}_{t-1}\right)
$$

where $\Pi_{t}$ is the realization of the target variable at time $t, \Pi_{t}^{*}$ is the forecast made for time $t$ at time $t-1, E$ is the operator that indicates a mathematical expectation, and $\mathrm{I}_{t}$ denotes the full information set available at time $t-1$. When expectation is identical to its conditional expectation on the relevant information set available for forecasting, forecast rationality occurs (Muth 1961).

Nevertheless, Muth's REH does not affirm the existence of perfect foresight as the expected values can deviate from the actual values due to inherent uncertainty in the economic system (Sheffrin 1983). Practically, it is not possible to characterize the real economic setting under circumstances where perfect foresight and economic certainty exist. At once, costly and publicly unattainable information leads to imperfect information, thereby imparting a certain degree of random error to the expectations formation process. This explains why Muth created his REH framework by assuming that expectations are formed based on the relevant economic structure given the publicly available information at the time the forecasts are made. The accepted forecast errors are reduced to the effect of economic uncertainty, imperfect information, or other unforeseen shock. Therefore, $\mathrm{REH}$ is realistically defined as:

$$
\Pi_{t}^{*}=E\left(\Pi_{t} \mid \Omega_{t-1}\right)+\eta_{t},
$$

where $\Omega_{t-1}$ in Equation (2) is the subset of the full information set $\left(\mathrm{I}_{t-1}\right)$ and $\eta_{t}$ designates the random error term. Rearranging Equation (2), we obtain:

$$
\eta_{t}=\Pi_{t}^{*}-E\left(\Pi_{t} \mid \Omega_{t-1}\right) .
$$

In Equation (3), the gap between the expected value and its realized value constitutes only non-systematic or random influences that demonstrate no distinct pattern, and its statistical significance is captured by the error term $\left(\eta_{t}\right)$ if forecast rationality occurs. Muth's rational framework implicitly suggested that a forecast is formed in an efficient manner through systematic processes while learning processes take place over time, and economic agents use this knowledge to perform future forecasting (Lane 1995). At long last, unsystematic forecast errors tend to be ruled out and expectations become approximately identical to their true value. Accordingly, three classical assumptions of forecast rationality must be empirically satisfied through REH testing. First, a rational framework requires that present forecast errors and past forecast errors do not exhibit an interdependent relationship, or autocorrelation. In other words, the random error term $\left(\eta_{t}\right)$ that accounts for all forecast errors needs to be consistent with the property of lack of serial correlation as defined in Equation (4) below:

$$
E\left(\eta_{t} \eta_{t-i}\right)=0
$$

Consequently, forecasts should also meet two other classic properties of rationality: unbiasedness and efficiency. The principle of unbiasedness requires that expectations be the unbiased predictor of the actual realized variable, implying that there is no systematic forecast error because regularity in the expectations formation process tends to be 
eliminated as continuous learning takes place over time. In the end, the true values, on average, will be equivalent to the expected values. Otherwise, economic agents would systematically overestimate or underestimate the realized value (Nielsen 2003). The unbiasedness property is depicted in Equation (5) as:

$$
E\left(\eta_{t}\right)=0 .
$$

Furthermore, Muth (1961) asserted that the expected series $\left(\Pi_{t}^{*}\right)$ must portray no significant serial correlation with its random error term $\left(\eta_{t}\right)$, signifying that the unconditional expected value of the forecast error has a zero mean. Implicitly, violating the property of lack of serial correlation also implies rejection of the unbiasedness property. Finally, the efficiency property requires that the forecast error, conditional on the current and past values of the predicted variable, have a mean of zero. In other words, it presumes that economic agents efficiently incorporate and utilize all available information regarding the past when forming future expectations. The principle of efficiency is expressed in Equation (6) as:

$$
E\left(\eta_{t} \mid \Pi_{t-1}, \Pi_{t-2}, \ldots\right)=0 .
$$

To validate the doctrine of rationality, rationality tests that include tests of unbiasedness, non-serial correlation, and efficiency have been proposed to verify each classic property underlying REH. However, Lopes (1998) claimed that the examples in Muth (1961) have popularized unbiasedness testing in examining the implications of REH. Hence, some researchers, such as Bakhashi and Yates (1998), and Aggarwal and Mohanty (2000) considered only unbiasedness in testing REH while others also tested the efficiency and/or orthogonality (see Kim 1997; Forsells, Kenny 2002; Gao et al. 2008).

\section{Data description and methodology}

\subsection{Data description}

In this study, the survey expectational data were extracted from the BESLC compiled by DOSM. The sample period covered in this study ranged from January 1978 through July 2007. DOSM collected the survey data on a bi-annual basis with the aim of gathering information on current and future economic trends in Malaysia. In terms of the selection of survey participants, a total of 270 companies encompassing both large public and private limited companies were selected based on a three-stage sample design. During the first stage of sample selection, the respective sectors' contribution to gross revenue, employment, and net value of the fixed assets in the overall business segment was evaluated to allocate the 270 companies among the sectors. Next, the representation of industries within each sector was derived from the industries' contribution to gross revenue in the sector. Ultimately, an individual company's contribution to gross revenue was calculated and used to select the companies within each industry.

\subsection{Time series properties of the data}

Earlier rationality testing based on regression analysis failed to account for the potential effect of using non-stationary time series data (Aggarwal et al. 1995; Nielsen 2003). However, Engle and Granger (1987) argued that neglecting the stationarity properties 
of time series data will create erroneous conclusions because inferences drawn from the regression estimations will be based on spurious regression results. Hence, this study used the Augmented Dickey-Fuller (ADF) unit root test developed by Dickey and Fuller (1979) and the Phillips-Perron (PP) unit root test put forward by Phillips and Perron (1988) to detect the existence of the unit root in the survey data that is also in the time series basis. In this preliminary test, a series $\mathrm{X}_{t}$ is said to be integrated to an order of $d$ if the series reaches stationarity after differencing $d$ times, and it can be mathematically symbolized by $\mathrm{X}_{t} \sim I(d)$.

\subsection{Cointegration test}

In addition to the preliminary testing of data stationarity, recent literature on REH testing has advocated the use of cointegration testing to examine the presence of co-movement in the survey expectational data. Aggarwal et al. (1995) claimed that stationary forecasts are a necessary, but not sufficient, requirement for a forecast to be unbiased. To distinguish the unbiased nature of the survey forecast if the realized series and the respective forecast series are non-stationary, Aggarwal et al. (1995) supported the use of cointegration testing. Granger (1986) also emphasized the significant implications of cointegration tests on survey-based studies. He stressed that the optimal forecast and the actual value of the series being predicted must be cointegrated under a relatively general condition; otherwise, the two series do not even own similar long-term properties. In this fashion, we drew the evidence of cointegration for a group of non-stationary series based on the Johansen and Juselius (1990) cointegration test. Note that from a different perspective, optimal forecasts refer to forecasts that provide the minimum error, based on forecasting accuracy criteria such as mean absolute percentage error as mentioned in Šečkutè and Pabedinskaitè (2003). Nevertheless, such criteria are beyond the scope of REH study.

\subsection{The rationality tests}

Muth's concept of REH suggested that, for a forecast to be generated under the doctrine of rationality, the subjective expectation must coincide with the corresponding mathematical expectation. Consequently, in the case of survey-based expectations, the properties of REH require that the survey expectations are unbiased predictors of future values. The unbiased nature of a forecast series can be empirically verified based on the unbiasedness test proposed by Theil (1966) by regressing the survey expectational series on the respective realizations according to the realizations-forecast regression (RFR) equation below:

$$
\Pi_{t}=\alpha+\beta \Pi_{t}^{*}+\eta_{t}
$$

where $\Pi_{t}$ in Equation (7) refers to the realization of the target variable at time $t, \Pi_{t}^{*}$ is the forecast of $\Pi_{t}$ generated at time $t-1$, and $\alpha$ and $\beta$ are the parameters of interest. $\eta_{t}$ denotes the random error term, which should hold the characteristics of zero mean and finite variance. In short, the random error term is assumed to be a white-noise process and serially uncorrelated with $\Pi_{t}^{*}$.

In Equation (7), the unbiasedness test was performed by jointly testing the hypotheses of $H_{0}:(\alpha, \beta)=(0,1)$ and $H_{1}:(\alpha, \beta) \neq(0,1)$. The estimation of $\alpha$ and $\beta$ was conducted 
using ordinary least squares (OLS), and the hypothesis was verified on the basis of the $F$-statistic. Rejection of the null hypothesis of unbiasedness implies the existence of a biased prediction, and the survey forecast cannot be regarded as a rational forecast of its actual realized series. Consequently, the forecaster is said to be systematically under- or overpredicting an economic variable over time (Forsells, Kenny 2002). A survey forecast tends to overestimate actual value if rejection of the null hypothesis of unbiasedness is due to the existence of $\beta$ value that is significantly less than one or unity (Aggarwal, Mohanty 2000).

Furthermore, the properties of REH additionally require that the forecast error must not possess any autocorrelation. In other words, the difference between the realized series and the forecast series cannot be serially correlated with past forecast errors. Thus, the forecast is said to be excused from the potential effect of unsystematic forecast errors if the forecast errors are free of serial correlation such that $E\left(\eta_{t} \eta_{t-i}\right)=0$. Following Evans and Gulamani (1984), the existence of serial correlation of forecast errors can be detected by estimating the regression in Equation (8) as follows:

$$
\eta_{t}=\delta_{0}+\sum_{i=1}^{p} \delta_{i} \eta_{t-i}+\varepsilon_{t},
$$

where $\eta_{t}$ is the forecast error and $p$ is the lag length with $i \in\{1,2,3, \ldots, p\}$. The joint null hypothesis can be defined as $H_{0}:\left(\delta_{0}, \delta_{i}\right)=0, i \in\{1,2,3, \ldots, p\}$. Rejection of the null hypothesis in Equation (8) indicates that there is no serial correlation between the forecast errors.

Finally, Muth's REH also requires that forecasters efficiently use all available information when forming expectations. If the efficiency requirement can be observed, then past values of the target variable are fully incorporated in explaining the error between realized values and expected values. This is a condition required for a set of survey expectational series to meet the term of weak-form efficiency. This property can be examined based on Mullineaux (1978) framework by estimating the following Equation (9):

$$
\eta_{t}=\varnothing_{0}+\sum_{i=1}^{N} \varnothing_{i} \Pi_{t-1}+\omega_{t}
$$

where $\eta_{t}$ is the forecast error and $\omega_{t}$ is the random disturbance term. $\varnothing_{0}$ and $\varnothing_{i}$ are the parameters to be estimated and to be restricted to zero in the joint hypothesis testing. Hence, the null hypothesis is defined as $H_{0}:\left(\varnothing_{0}, \varnothing_{i}\right)=0, i \in\{1,2,3, \ldots, N\}$. Rejection of the null hypothesis implies that survey forecasts do not satisfy the efficiency property as advocated by the concept of REH, indicating that survey participants do not use information from the past in an efficient manner while creating future forecasts.

\section{Empirical results and discussions}

The results of ADF and PP unit root tests for both realized and expected gross revenue and capital expenditures indicated that all involved series are non-stationary at level but attained stationarity at first difference, implying that all investigated series are integrated 
to the order of one, or follow the $I(1)$ stochastic process ${ }^{1}$. Then, we employed Johansen and Juselius (1990) cointegration test to draw the evidence of cointegration. The result is presented in Table 1.

In all cases, the null hypothesis of non-cointegration was firmly rejected as both the Trace and Maximum-Eigen statistics are statistically significant at the 5\% level. These results suggest the existence of co-movement between the excepted series and its respective realized series, and they are cointegrated with one cointegrating vector. In other words, the actual series and its respective forecast series are said to share a common stochastic trend and tend to converge to the similar equilibrium path in the long run. This evidence ensures that, at least in the long run, any modestly acceptable forecast series must not deviate far apart from the actual realized series.

However, for the forecast series to be regarded as a rational forecast of its realization series, the three necessary conditions noted by Fischer (1989) must be satisfied ${ }^{2}$. In this study, the results of unit root tests, as well as the Johansen and Juselius (1990) cointegration test, clearly complied with the requisites stated in Fischer (1989), indicating that the forecast series is a rational forecast of its actual series for both variables under study. However, satisfying the condition documented in Fischer (1989) is a necessary but insufficient condition for an investigated series to be regarded as rational in Muth's sense. Conversely, further direct tests on rationality are necessary to reinforce the validity of REH. Table 2 presents the empirical findings for RFR conventional unbiasedness testing proposed by Theil (1966). The regression estimates based on the OLS framework indicate that the slope coefficient is significantly positive at the $1 \%$ level in all cases, signifying that, on average, Malaysia's manufacturing firms predicted the direction of future changes correctly.

Table 1. Johansen and Juselius cointegration test results

\begin{tabular}{ccccccc}
\hline Variables & $\mathrm{H}_{0}$ & $\mathrm{H}_{1}$ & $\lambda$-trace & $\mathrm{H}_{0}$ & $\mathrm{H}_{1}$ & $\lambda$-max \\
\hline \multirow{2}{*}{ LAGR, LEGR } & $r=0$ & $r \geq 1$ & $18.638^{* *}$ & $r=0$ & $r=1$ & $18.095^{* *}$ \\
\cline { 2 - 7 } & $r \leq 1$ & $r \geq 2$ & 0.543 & $r \leq 1$ & $r=2$ & 0.543 \\
\hline \multirow{2}{*}{ LACE, LECE } & $r=0$ & $r \geq 1$ & $18.129^{* *}$ & $r=0$ & $r=1$ & $15.045^{* *}$ \\
\cline { 2 - 7 } & $r \leq 1$ & $r \geq 2$ & 3.084 & $r \leq 1$ & $r=2$ & 3.084 \\
\hline
\end{tabular}

Notes: LAGR, LACE, LEGR and LECE denote natural logarithms of actual gross revenue, actual capital expenditure, expected gross revenue, and expected capital expenditure, respectively. Asterisks $(* *)$ denote significant at the $5 \%$ level, $r$ is the number of cointegration vector(s). The critical values for $\lambda$-trace are 15.495 and 3.841 for $\mathrm{H}_{0}: r=0$ and $r \leq 1$. Alternatively, the critical values for $\lambda$-max are 14.265 and 3.841 for $\mathrm{H}_{0}: r=0$ and $\mathrm{H}_{0}: r \leq 1$, respectively.

\footnotetext{
${ }^{1}$ To conserve space, the unit root test results are not presented here, but they are available from the authors upon request.

${ }^{2}$ Fischer (1989) argued that in the context of REH, for an expectational series to be regarded as a rational forecast of its actual series, the survey-based forecast series $\left(\Pi_{t}^{*}\right)$ must be integrated in the $I(1)$ process, $\Pi_{t}$ and $\Pi_{t}^{*}$ must be cointegrated, and the cointegrating vector must be one.
} 
Table 2. Results of unbiasedness test

\begin{tabular}{lcc}
\hline & Gross Revenue & Capital Expenditure \\
\hline Constant $(\alpha)$ & 0.034 & 0.075 \\
\hline Slope $(\beta)$ & $0.999 * * *$ & $0.989^{* * *}$ \\
\hline R-squared & 0.996 & 0.945 \\
\hline & Hypothesis Testing & \\
\hline F-statistic $(\alpha=0, \beta=1)$ & $4.025(0.023)^{* *}$ & $0.077(0.926)$ \\
\hline LM $\chi^{2}(1)$ & $0.575(0.452)$ & $0.075(0.785)$ \\
\hline LM $\chi^{2}(2)$ & $2.400(0.100)$ & $1.823(0.171)$ \\
\hline
\end{tabular}

Note: Asterisks $(* * *)$ and $(* *)$ denote statistically significant at the $1 \%$ and $5 \%$ levels, respectively.

Furthermore, in the case of expectations on gross revenue, the joint hypothesis of $\alpha=0$, $\beta=1$ was firmly rejected at the $1 \%$ level, showing that business people in the manufacturing sector tend to be biased in the prediction of gross revenue, and these biased forecasts tend to overestimate the actual values of gross revenue since the slope coefficient is significantly less than 1 . On the other hand, those manufacturers do not exhibit biased prediction in their capital expenditures, as the joint hypothesis of $\alpha=0, \beta=1$ cannot be rejected. Hence, only prediction on capital expenditures is shown to successfully pass the unbiasedness test, suggesting that Malaysian manufacturers are more likely to be unbiased in forming expectations on capital expenditures. On the whole, the Lagrange multiplier (LM) test results reported in Table 2 show no evidence of serial correlation in all cases. As the disturbance terms or error terms in all series under study are white noise (Habibullah 2001), the residual of the RFR equation is consistent with the requirement of forecast rationality.

In subsequent rationality tests, we examined whether the survey data incorporated past information. The framework of REH requires that the difference between the realized series and the forecast series cannot be serially correlated with past forecast errors, a condition whereby there must no interdependent relationship between present forecast errors and past forecast errors. The results of the lack of serial correlation test drawn under the basis of the $F$-statistic are reported in Table 3 . The business operational forecasts formulated by forecasters in the manufacturing sector exhibit significant serial correlation with the lagged forecast values at lag one through lag four. However, this is only observable in the expectations on gross revenue, not in the case of capital expenditures. Thus, in general, business players in the manufacturing sector are correcting past mistakes while dealing with capital expenditures predictions, but continuously making systematic errors when calculating expectations on gross revenue.

It is important to note that validating properties of uncorrelated forecast errors and forecast unbiasedness are at minimum a necessary condition for REH, but they may not be sufficient for REH to be justifiable, as Muth's REH proposition requires that forecasters efficiently use all available information when forming expectations. The available information set in this context refers to the past actual values or past history of the 
Table 3. Results of non-serial correlation and weak-form efficiency Tests

\begin{tabular}{ccccc}
\hline \multirow{2}{*}{$\begin{array}{c}\text { Lag } \\
\text { Length }\end{array}$} & \multicolumn{2}{c}{ Non-Serial Correlation Test: } & \multicolumn{2}{c}{ Weak-Form Efficiency Test: } \\
\cline { 2 - 5 } & Gross Revenue & Capital Expenditure & Gross Revenue & Capital Expenditure \\
\hline \multicolumn{5}{c}{$F$-statistic with respect to lag length: } \\
\hline 1 & $4.529^{* * *}$ & 0.033 & $4.520^{* * *}$ & 1.732 \\
\hline 2 & $4.671^{* * *}$ & 1.219 & $6.831^{* * *}$ & 1.414 \\
\hline 3 & $4.408^{* * *}$ & 0.989 & $7.205^{* * *}$ & 1.198 \\
\hline 4 & $3.407^{* *}$ & 0.819 & $5.467^{* * *}$ & 1.210 \\
\hline
\end{tabular}

Note: Asterisks $(* * *)$ and $(* *)$ denote statistically significant at the $1 \%$ and $5 \%$ levels, respectively.

investigated variable. Similar to the test of lack of serial correlation, the result of weakform efficiency testing was drawn on the basis of the $F$-statistic up to four lagged past actual values, and this is reported in Table 3 as well. Clearly, the results of weak-form efficiency testing suggest the rejection of forecast efficiency in the case of gross revenue prediction at a significant level of $1 \%$. Conversely, Malaysian manufacturers are efficient in using available information while dealing with capital expenditures forecasts.

\section{Conclusion}

In the business context, the microeconomics assumptions of profit and utility maximization are particularly crucial. As a result, the framework of REH is much more appealing than other expectation formation mechanisms such as extrapolative or adaptive expectations. This is because REH is in line with the basic principles of maximizing behavior whereby people efficiently engage in their economic self-interests by acting rationally in predicting future economic variables. However, merely assuming the existence of such behavior without verifying it empirically is certainly inappropriate, especially in an increasingly dynamic economic environment that is filled with uncertainty. Thus, attempts to ascertain the validity of REH in a real world setting are essential as policy designs that are sensitive to the hypothesis of expectations formation or motivated by the assumptions of REH may not be effectively established without sufficient understanding of the way expectations are formed.

This study helped to transform BESLC survey data, specifically on the manufacturing sector, into economically meaningful findings that offer a better understanding of the validity of REH in Malaysia's business forecasting, mainly in business operational forecasting. The empirical evidence drawn from this study provided important insights into policy makers as well as business players since better understanding of the expectational behavior of business firms may help them to establish more effective measures for responding quickly to market changes.

To sum up, business players in the manufacturing sector only able to comply with the doctrine of forecasts rationality in capital expenditures, but they tend to be irrational in forecasting gross revenue. In addition, findings from the reported rationality tests sug- 
gest that the irrationality in gross revenue predictions is owing to biased forecasts and inefficiency in using past relevant information. Moreover, past mistakes are found to be serially correlated with the current information set, leading to the existence of irrational forecasts. In this sense, it is crucial to emphasize that the implication of information on forecast rationality is indeed substantial and requires sufficient inclusion in all future forecasts. Therefore, manufacturing firms in Malaysia are encouraged to incorporate more relevant information while dealing with gross revenue predictions to ensure more accurate and realistic forecasting.

In addition to its role with regard to information, one justification for the existence of irrational behavior in gross revenue prediction is that business revenue is intrinsically difficult to forecast as it is closely related to prices and market demand, and movements related to these two aspects are subject to a high degree of uncertainty. Surveys of business expectations sometimes do not comply with Muth's rational framework as forecast accuracy is neglected when the responding firms intend to convey attractive future prospects to strengthen business confidence rather than report an accurate business forecast that enables them to reflect the rational behavior of a typical profitmaximizing firm. This is because the way firms perceive their future prospects tends to serve as an indicator for their potential investors to evaluate the firm's future strengths and capability to grow. Hence, it becomes a business habit to behave optimistically in forecasting value-related variables such as gross revenue. This partly explains why we could perceive an overprediction in surveys of business forecasts.

Publicly accessible survey materials often serve as a platform for households and investors to evaluate firms' future outlook. Thus, they should reflect the real business outlook in the economy to assist decision makers in developing realistic future plans and making profitable decisions. To reach this goal, survey institutions play an essential role in strengthening business people's incentives to reveal accurate future forecasts. In tandem, business forecasters are encouraged to improve their forecast accuracy and contribute more rational business forecasts to survey institutions that offer survey materials to the public and private users. Importantly, the nature of expectations formation needs to be assessed regularly and must be taken into account when the element of expectation is to be a key input in all decision making and future planning.

\section{Acknowledgments}

The authors acknowledge the financial support of the Universiti Malaysia Sarawak and Fundamental Research Grant No. FRGS/05(27)781/2010(62). Any flaws are the responsibility of the authors.

\section{References}

Aggarwal, R.; Mohanty, S.; Song, F. 1995. Are survey forecasts of macroeconomic variables rational?, Journal of Business 68(1): 99-119. http://dx.doi.org/10.1086/296655

Aggarwal, R.; Mohanty, S. 2000. Rationality of Japanese macroeconomic survey forecasts: empirical evidence and comparisons with the US, Japan and the World Economy 12(1): 21-31. 
Baghestani, H.; Kianian, A. M. 1993. On the rationality of U.S. macroeconomics forecasts: evidence from a panel of professional forecasters, Applied Economics 25(7): 869-878.

http://dx.doi.org/10.1080/00036849300000066

Bakhashi, H.; Yates, A. 1998. Are UK inflation expectations rational?, Working Paper No. 81. Bank of England.

Beach, E. D.; Fernandez-Cornejo, J.; Uri, N. D. 1995. Testing the rational expectations hypothesis using survey data from vegetable growers in the USA, Journal of Economic Studies 22(6): 46-59. http://dx.doi.org/10.1108/01443589510099048

De Leeuw, F. D.; Mckelvey, M. J. 1981. Price expectations of business firms, Brookings Papers on Economic Activity 12(1): 299-314.

De Leeuw, F. D.; Mckelvey, M. J. 1984. Price expectations of business firms: bias in the short run and long run, American Economic Review 74(1): 99-110.

Dias, F.; Duarte, C.; Rua, A. 2010. Inflation expectations in the Euro area: are consumer rational?, Review of World Economics 146(3): 591-607. http://dx.doi.org/10.1007/s10290-010-0058-6

Dickey, D.; Fuller, W. 1979. Distribution of the estimators for autoregressive times series with a unit root, Journal of the American Statistical Association 74(366): 427-431.

http://dx.doi.org/10.2307/2286348

Dovern, J.; Weisser, J. 2008. Are they really rational? Assessing professional macro-economic forecasts from the G-7 countries, Working Paper No. 1447. Kiel Institute for the World Economy.

Engle, R. F.; Granger, C. W. J. 1987. Cointegration and error correction, estimation and testing, Econometrica 55(2): 251-276.

Evans, G.; Gulamani, R. 1984. Tests for rationality for the Carlson-Parkin inflation expectation data, Oxford Bulletin of Economics and Statistics 46(1): 1-19.

http://dx.doi.org/10.1111/j.1468-0084.1984.mp46001001.x

Fischer, A. M. 1989. Unit roots and survey data, Oxford Bulletin of Economics and Statistics 51(4): 451-463. http://dx.doi.org/10.1111/j.1468-0084.1989.mp51004006.x

Forsells, M.; Kenny, G. 2002. The rationality of consumers' inflation expectations: survey-based evidence for the Euro area, Working Paper No. 163. European Central Bank

Frankel, J. A.; Froot, K. A. 1987. Using survey data to test standard propositions regarding exchange rate expectations, American Economic Review 77(1): 133-153.

Gao, F.; Song, F. M.; Wang, J. 2008. Rational or irrational expectations? Evidence from China's stock market, Journal of Risk Finance 9(5): 432-448. http://dx.doi.org/10.1108/15265940810916102

Ghaffar, R. A.; Habibullah, M. S. 1987. Price expectation and the demand for money in Malaysia: some empirical evidence, Jurnal Ekonomi Malaysia 15(June): 33-42.

Granger, C. W. J. 1986. Developments in the study of cointegrated economic variables, Oxford Bulletin of Economics and Statistics 48(3): 213-228.

http://dx.doi.org/10.1111/j.1468-0084.1986.mp48003002.x

Habibullah, M. S. 1988. Price expectation formation and the demand for loans in a developing economy: the case of Malaysian agriculture, The Singapore Economic Review 33(1): 68-87.

Habibullah, M. S. 1994. Do business firm in developing economy make rational economic forecast? The evidence from Malaysia business expectations survey of limited companies, Asian Economies 23(4): 73-92.

Habibullah, M. S. 1996. Forecasting economic variables in the agricultural sector: testing rational expectations hypothesis on survey data, Pakistan Journal of Applied Economics 12(2): 171-184.

Habibullah, M. S. 2001. Rationality of insurance firms' forecasts: results of unbiasedness and efficiency tests, Malaysia Management Journal 5(1\&2): 107-117. 
Johansen, S.; Juselius, K. 1990. Maximum likelihood estimation and inference on cointegration with application to the demand for money, Oxford Bulletin of Economics and Statistics 52(2): 169-210. http://dx.doi.org/10.1111/j.1468-0084.1990.mp52002003.x

Kawasaki, S.; Zimmermann, K. F. 1986. Testing the rationality of price expectations for manufacturing firms, Applied Economics 18(12): 1335-1347. http://dx.doi.org/10.1080/00036848600000007

Keane, M. P.; Runkle, D. E. 1990. Are economic forecasts rational?, Quarterly Review 13(2) [Spring]: 26-33. Federal Reserve Bank of Minneapolis.

Kim, S. J. 1997. Testing the rationality of exchange rate and interest rate expectations: an empirical study of Australian survey-based expectations, Applied Economics 29(8): 1011-1022.

http://dx.doi.org/10.1080/000368497326408

Kozlinskis, V.; Guseva, K. 2006. Evaluation of some business macro environment forecasting methods, Journal of Business Economics and Management 7(3): 111-117.

Krause, G. A. 2000. Testing for the strong form of rational expectations with heterogeneously informed agents, Oxford Journals, Political Analysis 8(3): 285-305.

http://dx.doi.org/10.1093/oxfordjournals.pan.a029817

Lane, C. 1995. The rationality of rational expectations, The Student Economic Review. The University of Dublin: Trinity College. Available from Internet: http://www.tcd.ie/Economics/SER/ pasti.php?y=94.

Lopes, A. S. 1998. On the 'Restricted Cointegration Test' as a test of the rational expectations hypothesis, Applied Economics 30(2): 269-278. http://dx.doi.org/10.1080/000368498326065

Lovell, M. 1986. Tests of the rational expectations hypothesis, American Economic Review 76(1): $110-124$.

Madsen, J. B. 1993. The formation of production expectations in manufacturing industry for nine industrialized countries, Empirical Economic 18(3): 501-521.

http://dx.doi.org/10.1007/BF01176201

Marais, D. J.; Smit, E. V. D. M.; Conradie, W. J. 1997. Mirco-level tests for rationale expectations in South Africa, South Africa Journal of Business Management 8(1): 15-27.

Mitchell, K.; Pearce, D. K. 2007. Professional forecasts of interest rates and exchange rates: evidence from the Wall Street Journal's panel of economists, Journal of Macroeconomics 29(4): 840-854.

Mullineaux, D. J. 1978. On testing for rationality: another look at the Livingston price expectations data, The Journal of Political Economy 86(2): 329-336. http://dx.doi.org/10.1086/260672

Muth, J. F. 1961. Rational expectations and the theory of price movements, Econometrica 29(3): 315-335. http://dx.doi.org/10.2307/1909635

Nielsen, H. 2003. Inflation expectations in the EU-rational?, The Eighth Spring Meeting of Young Economists (April): 3-5. Catholic University of Leuven, Belgium.

Osterberg, W. P. 2000. New results on the rationality of survey measures of exchange-rate expectations, Federal Reserve Bank of Cleveland Economic Review 36(1): 14-21.

Philips, P. C. B.; Perron, P. 1988. Testing for a unit root in time series regression, Biometrika 75(2): 335-346. http://dx.doi.org/10.1093/biomet/75.2.335

Puah, C. H.; Chong, L. L. Y.; Jais, M. 2011. Testing the rational expectations hypothesis on the retail trade sector using survey data from Malaysia, Journal of International Business and Economics 11(4): 214-218.

Sheffrin, S. M. 1983. Rational Expectations. Cambridge: Cambridge University Press.

Ščkutè, L.; Pabedinskaite, A. 2003. Application of forecasting methods in business, Journal of Business Economics and Management 4(2): 144-157.

Theil, H. 1966. Applied Economic Forecasting. North-Holland: Amsterdam. 
Tompkinson, P.; Common, M. 1983. Evidence on the rationality of expectations in the British manufacturing sector, Applied Economics 15(4): 425-436.

http://dx.doi.org/10.1080/00036848300000014

Wong, S. S. L.; Puah, C. H.; Abu Mansor, S. 2011. Survey evidence on the rationality of business expectations: implications from the Malaysian agricultural sector, Journal of Economic Computation and Economic Cybernetics Studies and Research 45(4): 169-180.

Chin-Hong PUAH. Dr, is an Associate Professor and Associate Managing Editor of International Journal of Business and Society at the Faculty of Economics and Business, Universiti Malaysia Sarawak. He obtained his PhD degree majoring in Financial Economics from Universiti Putra Malaysia. He has more than 13 years of experience in teaching and research. His current area of research includes business economics, monetary economics and applied macroeconomics studies.

Shirly Siew-Ling WONG gained her Bachelor of Economics from Universiti Malaysia Sarawak and currently she is working as a research assistant cum tutor while pursuing her $\mathrm{PhD}$ study in Universiti Malaysia Sarawak.

Venus Khim-Sen LIEW. Dr, is an Associate Professor with the Faculty of Economics and Business, Universiti Malaysia Sarawak. He holds BSc degree in Mathematics, and Master of Economics and PhD degrees in Financial Economics from Universiti Putra Malaysia. His areas of expertise are in Statistics, Mathematics, Econometrics, Time Series Analysis, Financial Economics, Investment Analysis and Financial Modeling. His research interests include the applications of modeling, forecasting, and nonlinear time series analysis in international finance, financial economics, business and macroeconomics. 